\title{
Speech rates of New Zealand English- and American English-speaking children
}

\author{
MICHAEL P. ROBB \& GAIL T. GILLON \\ University of Canterbury, Christchurch, New Zealand
}

\begin{abstract}
Adult speakers of New Zealand English demonstrate faster speaking rates than adult speakers of Australian, American, or British English. Little, however, is known about comparability of speaking rates in children who speak different varieties of English. This study begins to address this need through examining articulation rate and overall speaking rate data for ten New Zealand English-speaking children (aged 3;1-3;5 years) and ten American English-speaking children (aged 2;11-3;5 years). The participants had typically developing speech and language skills and the data were collected from conversational language samples where the child was engaged in a play activity with a speech pathologist or parent. Both groups demonstrated significantly faster articulation rates compared to overall speaking rates. In addition, utterance length was significantly correlated with both speaking rate and articulation rate. Group differences were evident. Contrary to previous results reported for adults, the New Zealand children demonstrated slower overall speaking rates and slower articulation rates than the American children. Results of a vowel analysis indicated a higher percentage of lax vowel production and lower percentage of tense vowel production among the American children compared to New Zealand children, indicating that vowel differences were a contributing factor to the observed differences in speech rates. The clinical applicability of the present data is discussed.
\end{abstract}

Keywords: Articulation rate, children, speaking rate, New Zealand English.

\section{Introduction}

Measurement of speaking rate and articulation rate are two popular methods of determining how quickly someone is talking. Speaking rate is measured as the number of syllables produced in a connected speech sample divided by the time needed for completing the speech sample (Cotton, 1936; Grosjean \& Lane, 1974; Kelly \& Steer, 1949). Articulation rate is measured as the number of syllables produced in a timed speech sample following removal of silent intervals from the sample (Crystal \& House, 1990; Dankovicova, 1997; Goldman-Eisler, 1968; Miller, Grosjean, \& Lomanto, 1984). Speaking rate provides a general estimate of how quickly someone is talking and may vary considerably depending on factors such as the emotional state of the speaker, and the type of speaking situation (Hall, Amir, \& Yairi, 1999; Miller et al., 1984). Articulation rate provides a sensitive estimate of actual speech execution time as a result of removing silent intervals from the speech sample (Miller et al., 1984). A number of communication disorders result from aberrant speech timing patterns (e.g., the dysarthrias, stuttering). Speech pathologists rely on speech rate data for the identification and diagnosis of deviations in rate and for the management of speech timing disorders.

Some languages are spoken more quickly than others (Roach, 1998). The same can be said for some varieties of English. The source of these rate differences reflect segmental and suprasegmental characteristics of the specific language, as well as social and personal factors (Roach, 1998). Adult speakers of American English (AE) have an overall speaking rate of approximately 250 syllables per minute (spm) and articulation rate of approximately 300 spm (e.g., Chermak \& Schneiderman, 1986; Crystal \& House, 1990; Kent \& Forner, 1980; Kowal, O'Connel, \& Sabin, 1975; Robb, Maclagan, \& Chen, 2003a; Sharf \& Lehman, 1984; Tsao \& Weismer, 1997; Walker, 1988). Adult speakers of Australian English (AuE) have an overall speaking rate of approximately $230 \mathrm{spm}$ (Bernard, 1965; Block \& Killen, 1996), and adult speakers of British English (BE) have an overall speaking rate of approximately $260 \mathrm{spm}$ (Tauroza \& Allison, 1990). Adult speakers of New Zealand English (NZE) have an overall speaking rate and articulation rate

Correspondence: Michael Robb, Dept of Communication Disorders, University of Canterbury, Private Bag 4800, Christchurch 8020, New Zealand. 
of $280 \mathrm{spm}$ and $340 \mathrm{spm}$, respectively (Robb et al., 2003a). The general pattern that can be drawn from comparison of these four varieties of English is that adult speakers of NZE show the fastest speech rate and speakers of AuE show the slowest rate. The speaking rates of $\mathrm{AE}$ and $\mathrm{BE}$ fall somewhere between $\mathrm{AuE}$ and NZE. Within each variety of English there are no apparent gender differences for speaking rate and articulation rate. In addition, across all varieties of English, speaking rate and articulation rate are positively correlated with utterance length.

Compared to adults, speech rate data for children are less well represented across English varieties. A number of studies exist for AE-speaking children (e.g., Amster, 1984; Flipsen, 2002; Hall et al., 1999; Haselager, Slis, \& Rietveld, 1991; Kent \& Forner, 1980; Kowal et al., 1975; Pindzola, Jenkins, \& Lokken, 1989; Smith, Wasowicz, \& Preston, 1987; Walker, Archibald, Cherniak, \& Fish, 1992). Aside from these AE studies, we identified only two reports for nonAE-speaking children, both confined to AuEspeaking children (Block \& Killen, 1996; Robb, Gilbert, Reed, \& Bisson, 2003b). The AE and AuE studies vary in regard to subject age, sample size, and measurement technique, thus limiting direct comparison of the two English varieties. From the available data, cross-linguistic inferences can be made for 3-year-old and 9-year-old children. There seem to be no differences in articulation rate between 3-year-old AE- and AuE-speaking children, both demonstrating a rate of approximately $220 \mathrm{spm}$ (Hall et al., 1999; Robb et al., 2003b; Walker et al., 1992). Among 9-year-olds, AE children demonstrate a speaking rate in excess of $200 \mathrm{spm}$ (Haselager et al., 1991; Kowal et al., 1975); while AuE children demonstrate a speaking rate of approximately $175 \mathrm{spm}$ (Block \& Killen, 1996). On the basis of these comparisons, it would appear that rate differences among the $\mathrm{AE}$ and $\mathrm{AuE}$ varieties of English are not apparent in very young children. However, by 9years of age, when advances in both motor and language skills are firmly established (Chermak \& Schneiderman, 1986; Kent \& Forner, 1980; Kowal et al., 1975), speaking rate differences are apparent and maintained through adulthood. Clearly, a direct comparison of young children who differ according to language variety would assist in determining the age at which language-specific speaking rate differences occur.

A great deal remains to be learned regarding the speaking rate of children particularly those who speak a variety of English other than AE. Of special interest in the present study is the absence of data for NZEspeaking children. Past research comparing the speech rates of adult NZE and AE speakers identified a significantly faster rate among NZE speakers (Robb et al., 2003a). The researchers suggested that differences in rate were attributable to vowel production patterns unique to each language variety. Vowel raising is a common feature of NZE which contributes to shorter vowel durations (i.e., faster speaking rate) (Clark \& Yallop, 1995; Watson, Maclagan, \& Harrington, 2000). On the other hand, vowel lowering is a common feature of $\mathrm{AE}$ which contributes to longer vowel durations (i.e., slower speaking rate) (Labov, 1994).

To date, there have been no direct comparisons of speaking rate among children who speak different varieties of English. The purpose of the present study was to provide preliminary data regarding speaking rate and articulation rate in NZE-speaking 3-yearold children. Assuming the same pattern of vowel production and speaking rate observed for adult speakers of NZE and AE also occurs for children, it is plausible that young NZE children speak faster than young $\mathrm{AE}$ children. However, in light of past comparisons of 3-year-old AE-speaking and AuEspeaking children it is equally plausible that differences in rate may not be apparent in NZE and AE children at this young age. We were also interested in examining the relationship between utterance length and speaking rate. Past studies of adult speakers have found length of utterance to be positively correlated with speaking rate (Fonagy \& Magdics, 1960). However, data available for young children are less supportive of this pattern. Robb et al. (2003b) found a clear relationship between utterance length and speaking rate in 3-year-old AuE children, while Walker et al. (1992) found no such relationship in a similar age group of AE-speaking children. It was predicted that measures of overall speaking rate and articulation rate would be significantly correlated with utterance length for both NZE-speaking and AE-speaking children.

\section{Method}

\section{Participants}

Twenty children participated in the study. Ten children (four females, six males) were sampled in Christchurch, New Zealand and comprised the NZE group. Ten children (three females, seven males) were sampled from Iowa City, Iowa and comprised the $\mathrm{AE}$ group. The mean ages of the NZE and $\mathrm{AE}$ children were $3 ; 2$ years $(R=3 ; 1-3 ; 5$ years $)$ and $3 ; 1$ years $(\mathrm{R}=2 ; 1-3 ; 5$ years $)$, respectively. ${ }^{1}$ The children came from monolingual families. All children demonstrated normal language skills based on assessment instruments available to the researchers in their respective countries. The AE children were assessed using the Preschool Language Scale-3 (Zimmermann, Steiner, \& Pond, 1992), and the NZE children were assessed using the Peabody Picture Vocabulary Test-III (Dunn \& Dunn, 1997). Each child's speech articulation skills were evaluated using the Percentage of Consonants Correct-Revised (PCC-R) metric (Shriberg, Austin, Lewis, McSweeny, \& Wilson, 1997). ${ }^{2}$ Calculation of the PCC-R was based on analysis of 80 different 
words selected from a spontaneous speech sample. A child had to demonstrate a PCC-R score of $86 \%$ or greater to be included in the study. Formal audiological assessments were not performed. Based on behavioural observations, parental, and physician report, the children in each group were judged to demonstrate normal hearing abilities. The general characteristics of the children are listed in Table I.

\section{Speech sampling}

Each child was audio recorded once while engaged in spontaneous conversation with an adult (parent or speech pathologist) for approximately 30 minutes. In each situation the adult speaker spoke the same variety of English as the child. The topic of conversation was not held constant across children. The adult used open-ended questions posed to each child in a play context to elicit speech samples. The goal of each recording session was to collect approximately 30 multisyllabic utterances. Monosyllabic utterances were excluded from the database. Imitated utterances were not included in the analysis because of the possibility of imitations of the prosodic features of the adult. Aside from excluding monosyllabic and imitated utterances, no attempt was made to select utterances at pre-defined points across the language sample. Similar to the definition used by Hall et al. (1999), an utterance was defined as a string of words (syllables) that (1) communicated an idea, (2) was grammatically complete and (3) excluded non-speech sounds. An utterance was further defined as a string of syllables that did not contain a silent interval in excess of $250 \mathrm{~ms}$ (Flipsen, 2002; Miller et al., 1984; Tsao \& Weismer, 1997). A dynamic microphone and audio cassette recorder were used to collect the speech samples. No apparent deviations in voice pitch and loudness were observed during the recordings. The children were able to use a typical speaking voice devoid of "silly" or non-compliant vocal behaviours. Each recording was obtained in a carpeted, enclosed room perceptually judged by a researcher to be low in extraneous noise.

\section{Acoustic analysis}

The acoustic analysis was carried out using a commercially available speech analysis system (Kay CSL-4300B). The same researcher was responsible for analysis of NZE and AE samples. Each utterance was digitized at a $10 \mathrm{kHz}$ sampling rate and simultaneously displayed on a computer monitor as an amplitude-by-time waveform and wideband spectrogram ( $300 \mathrm{~Hz}$ bandwidth). On the basis of this dual display each utterance was measured for speaking rate and articulation rate as defined below.

Speaking rate. A pair of vertical cursors was positioned at the onset and offset of the first and last syllables in the utterance, respectively. Onset and offset points of the utterance were determined as the beginning and end points of visible acoustic energy. The time interval between the two cursors was recorded as the total utterance duration. Two measures of speaking rate were calculated for each utterance. The total number of syllables produced in each utterance was divided by the total utterance duration to determine spm. The total number of phones produced in each utterance was divided by the total utterance duration to determine the number of phones produced per second (pps). Perkins, Bell, Johnson, and Stocks (1979) and others (Flipsen, 2002; Hall et al., 1999) recommended calculation of phone rate over syllable rate because of the appreciable differences in length and phonetic composition of syllables. The resulting measure is thought to provide a direct index of the speed of speech sound production (Hall et al., 1999). Utterances were also grouped into short (2-4 syllables), medium (5-7 syllables) and long (8+ syllables) categories of syllable length and an average speaking rate for each category was calculated (Flipsen, 1999).

Articulation rate. Articulation rate was determined by dividing the number of syllables comprising each utterance by the total duration of the utterance with silent intervals longer than 50 ms deleted. ${ }^{3}$ A pair of vertical cursors was placed at the onset and offset of

Table I. Characteristics of the group of New Zealand English-speaking (NZE) children and American English-speaking (AE) children. The percentage of consonants correct-revised (PCC-R) metric, and standard scores for the Peabody Picture Vocabulary Test-III (PPVT-III) and the expressive communication and auditory comprehension sections of the Preschool Language Scale-3 (PLS) are reported.

\begin{tabular}{|c|c|c|c|c|c|c|c|c|c|c|}
\hline Group & Age & Sex & PCC-R & PPVT & Group & Age & Sex & PCC-R & PLS Expressive & PLS Receptive \\
\hline NZE1 & $3 ; 2$ & M & 92 & 102 & AE1 & $3 ; 2$ & $M$ & 90 & 102 & 108 \\
\hline NZE2 & $3 ; 2$ & $\mathrm{~F}$ & 91 & 110 & AE2 & $2 ; 11$ & M & 87 & 98 & 109 \\
\hline NZE3 & $3 ; 5$ & M & 90 & 110 & AE3 & $2 ; 11$ & $\mathrm{~F}$ & 88 & 102 & 106 \\
\hline NZE4 & $3 ; 3$ & M & 86 & 98 & AE4 & $3 ; 5$ & M & 86 & 108 & 106 \\
\hline NZE5 & $3 ; 1$ & $\mathrm{~F}$ & 86 & 107 & AE5 & $3 ; 5$ & $\mathrm{~F}$ & 97 & 111 & 116 \\
\hline NZE6 & $3 ; 2$ & $\mathrm{~F}$ & 88 & 107 & AE6 & $3 ; 0$ & M & 86 & 102 & 106 \\
\hline NZE7 & $3 ; 2$ & $\mathrm{~F}$ & 87 & 113 & AE7 & $3 ; 0$ & M & 91 & 98 & 111 \\
\hline NZE8 & $3 ; 5$ & M & 97 & 106 & AE8 & $3 ; 3$ & M & 92 & 110 & 115 \\
\hline NZE9 & $3 ; 4$ & M & 91 & 120 & AE9 & $3 ; 0$ & $\mathrm{~F}$ & 95 & 120 & 109 \\
\hline NZE10 & $3 ; 1$ & M & 90 & 101 & AE10 & $3 ; 1$ & M & 90 & 101 & 111 \\
\hline
\end{tabular}


each silent interval and the segment between the cursors was deleted from the waveform. After all silent intervals were removed, the time between onset and offset of the acoustic signal reflected the total duration of the utterance. The units of measure for articulation rate were the same as speaking rate (spm and pps). Utterances were also grouped into short ( $2-4$ syllables), medium ( $5-7$ syllables) and long (8 or more) syllable categories and an average articulation rate for each category was calculated.

\section{Vowel analysis}

The vowel types comprising each child's conversational speech sample were considered as a possible influencing factor on his/her subsequent speech rates. Each child's sample was phonetically transcribed using symbols of the International Phonetic Association (IPA). All transcriptions were performed by the first author. On the basis of each transcript, a vowel phonetic inventory was created for each child. Following the procedures described by StoelGammon and Dunn (1985), an independent analysis was performed that considered each child's vowel productions without reference to an adult/expected form. An independent analysis was preferred over a relational analysis (i.e., reference to expected form), thereby allowing for comparison within and between speaker groups. Identification of vowels was facilitated by examining the acoustic characteristics of each vowel as depicted in a wideband spectrogram. No attempt was made to control for vowel occurrence according to syllable position. The only requirement for a vowel to be included in a child's inventory was that it had to occur at least twice within the speech sample. Group data were also tabulated for vowel inventories. In order for a vowel to be included as part of the group inventory, it had to be produced by at least seven of the ten children (70\% occurrence). The per cent-occurrence of vowel types in each child's speech sample was also calculated and organized according to tongue elevation, tongue advancement, and tense/lax categories.

\section{Reliability}

Reliability of the acoustic measurements was assessed by re-measuring the speech samples provided by $20 \%$ of the participants (two NZE speakers and two AE speakers). Average absolute errors for overall speaking rate and articulation rate were $5 \mathrm{spm}$ and $3 \mathrm{spm}$, respectively. The Pearson product moment correlation coefficients for overall speaking rate and articulation rate between the first and second measurements were 0.99 and $0.98(p<0.05)$ respectively. Reliability of phonetic transcription was evaluated by having a second trained transcriber (a native speaker of NZE) independently analyse the entire speech samples of four children (two NZE and two AE). These transcriptions were then compared to those originally performed by the first author (a native speaker of $\mathrm{AE}$ ). The inter-judge agreement for consonant and vowel transcription was $92 \%$ and $85 \%$, respectively.

\section{Results}

\section{Speaking and articulation rates}

The average speaking rate for the NZE group was $182 \mathrm{spm}(\mathrm{SD}=48)$ and $7.15 \mathrm{pps}(\mathrm{SD}=1.86)$. The average articulation rate for the NZE group was $194 \mathrm{spm}(\mathrm{SD}=51)$ and $7.59 \mathrm{pps}(\mathrm{SD}=1.94)$. The average speaking rate for the $\mathrm{AE}$ group of children was $208 \mathrm{spm}(\mathrm{SD}=57)$ and $8.17 \mathrm{pps}(\mathrm{SD}=1.97)$. The average articulation rate for the AE group was $225 \mathrm{spm}(\mathrm{SD}=59)$ and $8.84 \mathrm{pps}(\mathrm{SD}=2.02)$. A series of $t$-tests were performed to determine if speaking rate significantly differed from articulation rate within and between language groups. The alpha level was divided equally among the 4 planned comparisons using the Bonferroni procedure, yielding a per-comparison alpha level of 0.0125 (0.05/ $4=0.0125$ ) (Kirk, 1982). For each group, speaking rate according to spm and pps was significantly slower than articulation rate $(p<0.0001)$. Between groups, speaking rate and articulation rate according to spm and pps was found to be significantly slower for the NZE group compared to AE group $(p<0.0001)$.

\section{Utterance length}

The total number of multisyllabic utterances collected across NZE-speaking children was 313, which totalled 1477 syllables. The utterances ranged in length from two to 12 syllables with a mean utterance length of 4.7 syllables. A total of 303 multisyllabic utterances were collected for the AE-speaking children, which totaled 1397 syllables and ranged from 2-13 syllables in length. The mean utterance length was 4.5 syllables. The average speaking rates and articulation rates according to utterance-length groupings are listed in Table II. The relationship of utterance length to speaking rate and articulation rate was examined by calculating Pearson product moment correlations. The correlations obtained for the NZE group were high (utterance length and speaking rate: $r=0.97$; utterance length and articulation rate: $r=0.96)$. High correlations were also obtained for the AE group (utterance length and speaking rate: $r=0.93$; utterance length and articulation rate: $r=0.92)$. For both groups of children there was a strong trend toward increases in speech rate corresponding to increases in utterance length.

\section{Vowel analysis}

Results of the vowel inventory analysis for the NZE and AE groups are listed in Table III. A wide variety 
of vowel types were found for both groups. Conspicuously absent in the NZE vowel inventories were the rhotic vowels $/ 3^{\circ}, x$. Results of the vowel analysis according to vowel articulation categories are listed in Table IV. Examination of the percentages according to tongue elevation categories indicated nearly identical occurrence in the production of high, mid, and low vowels for the NZE and AE groups. To evaluate whether the NZE and AE groups differed in their production of vowel types, a series of alphaadjusted $t$-tests were performed. Prior to performing the tests, the per cent-occurrence values were transformed to arcsine values. None of the tests were significant, indicating little difference between groups in the proportional occurrence of vowel articulation according to tongue elevation.

Analysis of the vowel results according to tongue advancement categories found the $\mathrm{AE}$ group to produce a significantly greater number of front vowels $(p<0.01)$ and significantly lower number of back vowels $(p<0.005)$ compared to the NZE group. The groups did not differ in their production of central vowels. The data were also examined according to the occurrence of tense and lax vowel production. The AE-speaking children produced a significantly greater number of lax vowels $(p<0.01)$ and significantly fewer tense vowels $(p<0.008)$ compared to the NZE-speaking children.

\section{Discussion}

One aim of the present research was to determine if measures of speaking rate and articulation rate differentiated New Zealand and American varieties of English, as spoken by 3-year-old children. Based on past research among adult speakers of NZE and $\mathrm{AE}$, as well as cross-linguistic comparisons of $\mathrm{AE}$ and AuE children, one of two outcomes was expected, (1) NZE-speaking children would demonstrate a significantly faster rate compared to AE-speaking children, or (2) no differences would be apparent between the groups because of the young age at which they were sampled. Interestingly, neither of these outcomes was observed. Rather, the NZEspeaking children spoke using a significantly slower speaking rate and articulation rate compared to the AE-speaking children. The speaking rate and articulation rates calculated for the $\mathrm{AE}$ children are consistent with previously reported rates for 3-yearold $\mathrm{AE}$ and AuE-speaking children (Robb et al., 2003b; Walker et al., 1992).

Two possibilities are proposed to account for the significantly slower rates among the NZE speakers. The first is to consider the utterance samples collected across the two language groups. Assuming speaking rate is likely to increase as a function of increasing utterance length (Fonagy \& Magdics,

Table II. Average speaking rate (SR) and articulation rate (AR) for New Zealand English-speaking (NZE) and American English-speaking (AE) children. Overall speech rate and speech rate according to utterances of varying syllabic length are reported in syllables per minute (SPM) and phones per second (PPS). Standard deviations for the various rate calculations are shown in parentheses.

\begin{tabular}{|c|c|c|c|c|c|c|c|c|c|}
\hline \multirow[b]{2}{*}{ Utterance Length } & \multicolumn{2}{|c|}{ NZE SR } & \multicolumn{2}{|c|}{ NZE AR } & \multirow[b]{2}{*}{ Utterance Length } & \multicolumn{2}{|c|}{ AE SR } & \multicolumn{2}{|c|}{ AE AR } \\
\hline & SPM & PPS & SPM & PPS & & SPM & PPS & SPM & PPS \\
\hline $2-4$ Syll $(n=167)$ & $168(42)$ & $6.66(1.74)$ & $180(48)$ & $7.12(1.88)$ & $2-4$ Syll $(n=143)$ & $204(63)$ & $7.84(2.00)$ & $222(67)$ & $8.57(2.18)$ \\
\hline $5-7$ Syll $(n=112)$ & $197(49)$ & $7.59(1.83)$ & $209(52)$ & $8.04(1.93)$ & $5-7$ Syll $(n=134)$ & $208(50)$ & $8.37(1.83)$ & $225(51)$ & $9.02(1.81)$ \\
\hline $8+$ Syll $(n=34)$ & $210(47)$ & $8.24(1.78)$ & $219(44)$ & $9.59(1.62)$ & $8+$ Syll $(n=26)$ & $229(51)$ & $8.98(2.20)$ & $241(52)$ & $9.38(2.12)$ \\
\hline Overall & $182(48)$ & $7.15(1.86)$ & $194(51)$ & $7.59(1.94)$ & & $208(57)$ & $8.17(1.97)$ & $225(59)$ & $8.84(2.02)$ \\
\hline
\end{tabular}

Table III. Vowel inventories for New Zealand English-speaking (NZE) and American English-speaking (AE) children. The Per cent occurrence of each vowel type within each group is reported.

\begin{tabular}{|c|c|c|c|c|c|c|c|c|c|c|c|c|c|c|}
\hline \multicolumn{15}{|c|}{ Vowel Type } \\
\hline Group Occurrence & $\mathrm{i}$ & $\mathrm{e}$ & $\mathrm{u}$ & o & $\mathrm{p}$ & I & $\varepsilon$ & $\mathfrak{x}$ & a & $\Lambda$ & อ & $U$ & $3^{n}$ & $x$ \\
\hline NZE Children & 14 & 6 & 6 & 9 & 7 & 18 & 8 & 3 & 15 & 9 & 2 & 3 & 0 & 0 \\
\hline AE Children & 11 & 5 & 3 & 6 & 5 & 22 & 11 & 7 & 13 & 7 & 3 & 3 & 2 & 2 \\
\hline
\end{tabular}

Table IV. Average percentage of occurrence of vowel types according to tongue elevation, tongue advancement, and tense/lax categories for New Zealand English-speaking (NZE) and American English-speaking (AE) children. Standard deviations are shown in parentheses.

\begin{tabular}{llllllllr}
\hline & \multicolumn{7}{c}{ Vowel Articulation } \\
\cline { 2 - 8 } & High & Mid & Low & Front & Central & Back & Tense & Lax \\
\hline NZE Children & $40(6)$ & $50(8)$ & $10(4)$ & $49(6)$ & $25(3)$ & $26(4)$ & $45(6)$ & $55(7)$ \\
AE Children & $39(6)$ & $49(4)$ & $12(4)$ & $56(5)$ & $24(5)$ & $20(2)$ & $37(6)$ & $63(7)$ \\
\hline
\end{tabular}


1960), an uneven distribution of utterances collected across the two groups may have influenced the results. Examination of the total number of utterances collected according to utterance groupings does not provide strong support for this contention. The overall percentages of utterances measured for speaking rate containing short, medium, and long utterances for the NZE speakers was $53 \%, 36 \%$, and $11 \%$, respectively. The percentages of short, medium, and long utterances collected for the $\mathrm{AE}$ speakers were $47 \%, 44 \%$, and $9 \%$, respectively. Although it is possible that the slightly greater number of short utterances collected for the NZE group was responsible for the overall slower speaking rate and articulation rate, it is important to note that the $\mathrm{AE}$ group consistently demonstrated a faster rate for each utterance length.

Another possibility for the slower speaking and articulation rates among the NZE children is to consider the vowel composition of the speech samples. Past research among adult NZE and AEspeaking groups found both speaking rate and articulation rate to be faster among NZE speakers (Robb et al., 2003a). This difference in rate was attributed to vowel features of the two languages. Vowel raising occurs in NZE which naturally contributes to shorter vowel durations (Watson et al., 2000). Alternatively, vowel lowering occurs in $\mathrm{AE}$ which would contribute to longer vowel durations (Labov, 1994). Examination of the vowel productions in the present group of children indicated little difference in the production of low, mid, and high vowels. However, this finding would suggest that the two groups would show comparable speaking rates, rather than $\mathrm{AE}$ children speaking faster than NZE children. Further insight is gained by considering the occurrence of tense and lax vowels in the NZE and AE speech samples. Lax vowels are generally produced with shorter duration and are perceptually less distinct than tense vowels (Edwards \& Shriberg, 1983). In the present study, nearly two-thirds of the vowels produced by the $\mathrm{AE}$ children consisted of lax vowels. The predominance of lax vowel productions was also evident in a significantly greater proportion of front vowels (the majority of which are lax) among the $\mathrm{AE}$ speakers. On the other hand, the NZE children produced fewer lax vowels and more tense vowels compared to the $\mathrm{AE}$ children. The greater use of tense vowels by NZE children was also evident in a significantly greater proportion of back vowels (the majority of which are tense) compared to AE children. On the basis of these analyses, it appears that (1) vowel raising is not yet established in the vowel inventories of young NZE-speaking children by 3 years of age, and (2) differential vowel development occurs between NZE-speaking and AE-speaking children.

Another aim of the present research was to determine if these children altered their speaking and articulation rate according to length of utterance.
The results of past research examining speaking rate in 3-year-old children have been mixed with two reports indicating a strong relationship between rate and utterance length (Amster, 1984; Robb et al., 2003b), and another study indicating otherwise (Walker et al., 1992). The present results support the earlier findings of Amster (1984) and Robb et al. (2003b). Regardless of the differences in speaking rate observed between the two groups, the children increased their rates with corresponding increases in utterance length. Children in the NZE group showed a larger increase in syllable rate and phone rate from short to long utterance groupings relative to the $\mathrm{AE}$ children. However, comparison of the NZE and AE children at each utterance grouping consistently indicated slower rates for the NZE children.

The rate differences observed between the two groups of children may be of clinical relevance to speech pathologists. These professionals rely on speaking rate data for the assessment and treatment of speech timing disorders, such as stuttering (Neilson \& Andrews, 1993). Therefore, compilation of speech rate data for each variety of English spoken by adults and children is an important clinical goal. Although there have been a number of studies examining speaking rate in $\mathrm{AE}$ children, this is the first such study examining syllable rate and phone rate among children who speak NZE. Admittedly, the subject sample was small and therefore caution is warranted regarding generalizing these results to the population of NZE-speaking children. However, these data provide a good first step in the establishment of accurate normative data about NZE speaking rate for clinicians.

The results of this study support the earlier observations by Roach (1998) that some languages are spoken more quickly than others. This appears to be the case for two varieties of English spoken by children as young as 3 years of age. The present results paired with an earlier study of adult speakers of NZE and AE (Robb et al., 2003a) elicits the question, At what point in development does the rate of NZE-speakers surpass AE-speakers? The answer to this question awaits detailed developmental study of children acquiring the New Zealand language. NZE is the newest native-speaker variety of English in the world, developing sometime between 1840 and 1880 (Trudgill, Gordon, Lewis, \& Maclagan, 2000). The "newness" of the language, along with the geographic isolation and small population of the country are factors likely responsible for the paucity of speech research in this variety of English. Examining languages such as NZE, however, can equally contribute to a better understanding of the complex processes of speech production.

\section{Acknowledgements}

The authors sincerely appreciate the cooperation of the parents and children who participated in this 
research. Professor Patricia Zebrowski supplied the speech samples of the children from Iowa. Toby Macrae performed the phonetic transcriptions related to the inter-judge reliability assessment.

\section{Notes}

1. Previous investigators of speaking rate in children have either collected a large number of utterances per child across a small subject sample (Hall et al., 1999; Robb et al., 2003b) or collected 15 (or fewer) utterances per child across a large subject sample (Flipsen, 2002; Walker et al., 1992). The present study closely followed the methodology of Robb et al. (2003b).

2. Shriberg et al. (1997) recommended calculation of the percentage of consonant correct-revised (PCC-R) metric to evaluate accuracy of speech sound production. The PCC-R expresses the percentage of intended consonant sounds in a conversational sample that are articulated correctly. The PCC$\mathrm{R}$ considers consonant deletions and substitutions as inaccurate; however consonant distortions are scored as correct.

3. At present there is no consensus regarding the measurement of articulation rate. The lack of consensus centres on the measurement of silent intervals occurring within a speech sample. Some researchers only remove silent intervals of 150 $250 \mathrm{~ms}$ or longer (Flipsen, 2002; Grosjean \& Collins, 1979; Hammen \& Yorkston, 1996; Tsao \& Weismer, 1997). The rationale for including silent intervals of $150 \mathrm{~ms}$ or less as part of articulation rate is that these intervals may be associated with articulatory events occurring in the vocal tract during speech production. These silent intervals may be caused by respiratory, phonatory or articulatory processes (Tosi, 1974). However, some researchers believe it is inappropriate to infer articulatory activity on the complete absence of acoustic energy. Silent periods as short as $50 \mathrm{~ms}$ may, therefore, be removed from the original utterance (Chen, 1999; Deputy, Nakasone, \& Tosi, 1982; Robb et al., 2003a). Measurement of articulation rate according to this latter criterion is considerably more labour intensive in regards to waveform editing. The present researchers chose to remove all silent periods in excess of $50 \mathrm{~ms}$ when calculating articulation rate.

\section{References}

Amster, B. (1984). The rate of speech in normal preschool children. Unpublished doctoral dissertation, Temple University, Philadelphia, PA.

Bernard, J. (1965). Rates of utterance in Australian dialectic groups. Occasional Paper No. 7. University of Sydney: Australian Language Research Centre.

Block, S., \& Killen, D. (1996). Speech rates of Australian Englishspeaking children and adults. Australian fournal of Human Communication Disorders, 24, 39-44.

(2) \& Unwin.

Chen, Y. (1999). Acoustic characteristics of American English produced by native speakers of Mandarin. Unpublished doctoral dissertation, University of Connecticut, Storrs, CT.

Chermak, G., \& Schneiderman, C. (1986). Speech timing variability of children and adults. Fournal of Phonetics, 13, $477-480$.

Clark, J., \& Yallop, C. (1995). Phonetics \& phonology, second edition. Oxford: Blackwell.

Cotton, J. (1936). Syllabic rate: A new concept in the study of speech rate variation. Speech Monographs, 2, 112-117.

Crystal, T., \& House, A. (1990). Articulation rate and the duration of syllables and stress groups in connected speech. Fournal of the Acoustical Society of America, 88, 101-112.

Dankovicova, J. (1997). The domain of articulation rate variation in Czech. Fournal of Phonetics, 25, 287-312.
Deputy, P., Nakasone, H., \& Tosi, O. (1982). Analysis of pauses occurring in the speech of children with consistent misarticulations. Fournal of Communication Disorders, 15, 43-54.

Dunn, L., \& Dunn, L. (1997). Peabody picture vocabulary test, third edition. Circle Pines, MN: American Guidance Service.

Edwards, M., \& Shriberg, L. (1983). Phonology: Applications in communicative disorders. San Diego, CA: College-Hill Press.

Flipsen, P. (1999). Longitudinal data on articulation rate and production unit length in children with speech delay. Phonology Project Technical Report No. 9. Madison, WI: University of Wisconsin.

Flipsen, P. (2002). Longitudinal changes in articulation rate and phonetic phrase length in children with speech delay. Fournal of Speech, Language, and Hearing Research, 45, 100-110.

Fonagy, I., \& Magdics, K. (1960). Speed of utterance in phrases of different lengths. Language and Speech, 4, 179-192.

Goldman-Eisler, F. (1968). Psycholinguistics: experiments in spontaneous speech. London: Academic Press.

Grosjean, F., \& Collins, M. (1979). Breathing, pausing and reading. Phonetica, 36, 98-114.

Grosjean, F., \& Lane, H. (1974). Effects of two temporal variables on the listener's perception of reading rate. Fournal of Experimental Psychology, 102, 893-896.

Hall, K., Amir, O., \& Yairi, E. (1999). A longitudinal investigation of speaking rate in preschool children who stutter. Fournal of Speech, Language, and Hearing Research, 42, 1367-1377.

Hammen, V., \& Yorkston, K. (1996). Speech and pause characteristics following speech rate reduction in hypokinetic dysarthria. Fournal of Communication Disorders, 29, 429-445.

Haselager, G., Slis, I., \& Rietveld, A. (1991). An alternative method of studying the development of speech rate. Clinical Linguistics and Phonetics, 5, 53-63.

Kelly, J., \& Steer, M. (1949). Revised concept of rate. fournal of Speech and Hearing Disorders, 14, 222-227.

Kent, R., \& Forner, L. (1980). Speech segment durations in sentence recitations by children and adults. Fournal of Phonetics, $8,157-168$.

Kirk, R. (1982). Experimental design: Procedures for the behavioral sciences. Belmont, CA: Brooks-Cole Publishing.

Kowal, S., O'Connell, D., \& Sabin, E. (1975). Development of temporal patterning and vocal hesitations in spontaneous narratives. Fournal of Psycholinguistic Research, 4, 195-207.

Labov, W. (1994). Principles of linguistic change. Volume 1: Internal factors. Oxford: Blackwell.

Miller, J. (1981). Analyzing language production in children: Experimental procedures. Baltimore, MD: University Park Press.

Miller, J., Grosjean, F., \& Lomanto, C. (1984). Articulation rate and its variability in spontaneous speech: A reanalysis and some implications. Phonetica, 41, 215-225.

Neilson, M., \& Andrews, G. (1993). Intensive fluency training in chronic stutterers. In R. Curlee (Ed.), Stuttering and related disorders of fluency (pp. 139-165). New York: Thieme Medical Publishers.

Perkins, W., Bell, J., Johnson, L., \& Stocks, J. (1979). Phone rate and the effective planning time hypothesis of stuttering. Fournal of Speech and Hearing Research, 22, ????.

Pindzola, R., Jenkins, M., \& Lokken, K. (1989). Speaking rates of young children. Language, Speech, and Hearing Services in Schools, 20, 133-138.

Roach, P. (1998). Some languages are spoken more quickly than others. In L. Bauer \& P. Trudgill (Eds.), Language myths (pp. 150 - 158). London: Penguin Books.

Robb, M., Gilbert, H., Reed, V., \& Bisson, A. (2003b). A preliminary study of speech rates in young Australian Englishspeaking children. Contemporary Issues in Communication Science and Disorders, 30, 84-91.

Robb, M., Maclagan, M., \& Chen, Y. (2003a). Speaking rates of American and New Zealand varieties of English. Clinical Linguistics and Phonetics, 17, 1-15.

Sharf, D., \& Lehman, M. (1984). Relationship between the speech characteristics and effectiveness of telephone interviewers. Fournal of Phonetics, 12, 219-228. 
Shriberg, L., Lewis, B., McSweeny, J., \& Wilson, D. (1977). The percentage of consonants correct (PCC) metric: Extensions and reliability data. Fournal of Speech, Language, and Hearing Research, 40, 708-722.

Smith, B., Wasowicz, J., \& Preston, J. (1987). Temporal characteristics of the speech of normal and elderly adults. Journal of Speech and Hearing Research, 30, 522-529.

Stoel-Gammon, C., \& Dunn, C. (1985). Normal and disordered phonology in children. Baltimore, MD: University Park Press.

Tauroza, S., \& Allison, D. (1990). Speech rates in British English. Applied Linguistics, 11, 90-105.

Tosi, O. (1974). Measurement of low levels of acoustic energy. World papers in phonetics: Festschrift for Dr. Onishi's Kiju (pp. 129 -144). Kyoto: The Phonetic Society of Japan.

Trudgill, P., Gordon, E., Lewis, G., \& Maclagan, M. (2000). Determinism in new-dialect formation and the genesis of New Zealand English. Fournal of Linguistics, 3, 299-318.
Tsao, Y., \& Weismer, G. (1997). Interspeaker variation in habitual speaking rate: Evidence for a neuromuscular component. fournal of Speech, Language, and Hearing Research, 40, $858-$ 866.

Walker, J., Archibald, L., Cherniak, S., \& Fish, V. (1992). Articulation rate in 3- and 5-year-old children. Fournal of Speech and Hearing Research, 35, 4-13.

Walker, V. (1988). Durational characteristics of young adults during speaking and reading tasks. Folia Phoniatrica, 40, $13-20$.

Watson, C., Maclagan, M., \& Harrington, J. (2000). Acoustic evidence for vowel change in New Zealand English. Language Variation and Change, 12, 51-68.

Zimmermann, I., Steiner, V., \& Pond, R. (1992). Preschool language scale-3. San Antonio, TX: The Psychological Corporation. 